\title{
Diagnostic and prognostic utility of cardiovascular magnetic resonance imaging in heart failure with preserved ejection fraction - implications for clinical trials
}

Prathap Kanagala ${ }^{1 *}$ (D, Adrian S. H. Cheng ${ }^{1,2,3}$, Anvesha Singh ${ }^{1}$, John McAdam ${ }^{1}$, Anna-Marie Marsh', Jayanth R. Arnold', lain B. Squire ${ }^{1,4}$, Leong L. Ng ${ }^{1,5}$ and Gerry P. McCann ${ }^{1,6}$

\begin{abstract}
Background: Heart failure with preserved ejection fraction (HFpEF) is a poorly characterized condition. We aimed to phenotype patients with HFpEF using multiparametric stress cardiovascular magnetic resonance imaging (CMR) and to assess the relationship to clinical outcomes.

Methods: One hundred and fifty four patients (51\% male, mean age $72 \pm 10$ years) with a diagnosis of HFpEF underwent transthoracic echocardiography and CMR during a single study visit. The CMR protocol comprised cine, stress/rest perfusion and late gadolinium enhancement imaging on a 3T scanner. Follow-up outcome data (death and heart failure hospitalization) were captured after a minimum of 6 months.

Results: CMR detected previously undiagnosed pathology in 42 patients (27\%), who had similar baseline characteristics to those without a new diagnosis. These diagnoses consisted of: coronary artery disease ( $n=20$, including 14 with 'silent' infarction), microvascular dysfunction ( $n=11)$, probable or definite hypertrophic cardiomyopathy $(n=10)$ and constrictive pericarditis $(n=5)$. Four patients had dual pathology. During follow-up (median 623 days), patients with a new CMR diagnosis were at higher risk of adverse outcome for the composite endpoint (log rank test: $p=0.047$ ). In multivariate Cox proportional hazards analysis, a new CMR diagnosis was the strongest independent predictor of adverse outcome (hazard ratio: $1.92 ; 95 \%$ Cl: 1.07 to $3.45 ; p=0.03$ ).
\end{abstract}

Conclusions: CMR diagnosed new significant pathology in 27\% of patients with HFpEF. These patients were at increased risk of death and heart failure hospitalization.

Trial registration: ClinicalTrials.gov Identifier: NCT03050593. Retrospectively registered; Date of registration: February 06, 2017.

Keywords: Cardiovascular magnetic resonance imaging, Heart failure, Heart failure with preserved ejection fraction, Diagnostic, Prognostic, Transthoracic echocardiography

\footnotetext{
* Correspondence: pkk12@leicester.ac.uk

${ }^{1}$ Department of Cardiovascular Sciences and National Institute for Health

Research (NIHR), University of Leicester, Leicester Cardiovascular Biomedical

Research Unit, Glenfield Hospital, Groby Road, Leicester LE3 9QP, UK

Full list of author information is available at the end of the article
}

\section{Biomed Central}

(c) The Author(s). 2018 Open Access This article is distributed under the terms of the Creative Commons Attribution 4.0 International License (http://creativecommons.org/licenses/by/4.0/), which permits unrestricted use, distribution, and reproduction in any medium, provided you give appropriate credit to the original author(s) and the source, provide a link to the Creative Commons license, and indicate if changes were made. The Creative Commons Public Domain Dedication waiver (http://creativecommons.org/publicdomain/zero/1.0/) applies to the data made available in this article, unless otherwise stated. 


\section{Background}

Heart failure with preserved ejection fraction (HFpEF) presents with marked clinical heterogeneity and accounts for approximately half of all heart failure (HF) cases. It is projected to be the predominant phenotype in the near future $[1,2]$. While treatments have improved outcomes in heart failure with reduced ejection fraction (HFrEF), similar therapies have not been shown to improve outcome in HFpEF and there remain no specific, evidence-based treatments [3]. Furthermore, a wide range of pathologies such as silent myocardial infarction (MI) and ischaemia due to coronary artery disease (CAD), hypertrophic cardiomyopathy (HCM) and constrictive pericarditis may masquerade as HFpEF [4-6]. These 'phenocopies' may share many features of HFpEF such as preserved ejection fraction (EF), left ventricular hypertrophy $(\mathrm{LVH})$, diastolic dysfunction, atrial dilatation and elevated natriuretic peptides. Hence, focus has shifted to studying 'purer' forms of HFpEF by excluding such conditions from contemporary clinical trials [7].

Transthoracic echocardiography (TTE) remains the primary diagnostic tool for HFpEF [8] and the gatekeeper for entry into clinical trials of this entity [3, 7]. However, cardiovascular magnetic resonance imaging (CMR) is the recognized gold standard for assessment of the majority of parameters that make up the latest HFpEF guidelines [811]. The superior diagnostic capabilities of CMR across the spectrum of aforementioned 'phenocopies' is also well established [5, 12-14]. However, no reports in the literature detail the systematic use of CMR in patients with suspected HFpEF. We aimed to establish the proportion of new clinical diagnoses in HFpEF patients identified with CMR, and to assess their impact upon clinical outcome.

\section{Methods}

\section{Study population}

Patients were recruited as part of an observational cohort study conducted at a single tertiary cardiac centre. The inclusion criteria were: clinical or radiographic evidence of HF, EF $>50 \%$ on transthoracic echocardiography (TTE) and age $\geq 18$ years. The exclusion criteria were: $\mathrm{MI}$ in the preceding 6 months, suspected or confirmed cardiomyopathy or constrictive pericarditis, non-cardiovascular life expectancy $<6$ months, severe native valve disease, severe chronic obstructive pulmonary disease (or forced expiratory volume $\left[\mathrm{FEV}_{1}\right]<30 \%$ predicted or forced vital capacity $[\mathrm{FVC}]<50 \%$ predicted) and estimated glomerular filtration rate $($ eGFR $)<30 \mathrm{ml} / \mathrm{min}$ per $1.73 \mathrm{~m}^{2}$. The study was approved by the National Research Ethics Service. All subjects provided written informed consent prior to participation.

Potentially eligible patients were invited to participate following screening of the hospital database, outpatient clinics and wards. All enrolled patients underwent comprehensive clinical assessment (including patient reporting of angina symptoms and previous MI or revascularization), venepuncture, 12-lead electrocardiography (ECG) and TTE followed by CMR (provided no contraindications) during the same visit. The clinical reports of all scans were disseminated to the responsible physician(s) to inform patient management.

\section{Blood samples}

Blood was sampled for B-type natriuretic peptide (BNP) immunoassay (Siemens, Erlangen, Germany) and other biochemical markers (sodium, urea and creatinine). Estimated GFR was calculated from the Modification of Diet in Renal Disease formula.

\section{ECG}

The 12-lead ECGs performed were assessed (by PK and AMM) for the presence of pathological Q waves as surrogates of transmural MI [15].

\section{Imaging}

Clinical reports were generated for TTE and CMR scans with knowledge of patient demographics and past medical history (e.g. history of hypertension). All subsequent quantitative and qualitative analyses used to generate the reports were performed independently with readers blinded to data from the other scan. Image quality was graded as: $0=$ non-interpretable; $1=$ poor; $2=$ fair; $3=$ good.

\section{TTE}

TTE studies were performed and reported by two accredited sonographers (AMM, JM). Images were acquired and reported as per American Society of Echocardiography guidelines using an iE 33 system with S5-1 transducer (Philips Medical Systems, Best, The Netherlands) [16]. Left ventricular (LV) EF for study inclusion was calculated using the biplane method or estimated visually in cases of poor endocardial border definition. For borderline cases, final consensus required review by a third observer (PK). Any regional wall motion abnormalities (RWMA) were reported.

\section{CMR}

CMR scans were performed on a 3T scanner (Siemens Skyra Erlangen, Germany) with an 18-channel cardiac coil. The protocol was previously reported by our group [17]. Cine imaging was performed in three long axes and a short axis cine stack was performed in the interval between stress and rest perfusion acquisitions. For pharmacological stress, $140-210 \mathrm{mcg} / \mathrm{kg} / \mathrm{min}$ adenosine (depending on haemodynamic and symptomatic response) was infused for at least $3 \mathrm{~min}$. Stress and rest perfusion images at the basal, mid-ventricular and apical levels were acquired after 
injection of $0.04 \mathrm{mmol} / \mathrm{kg}$ of contrast (Gadovist, Bayer Healthcare, Berlin, Germany). Following rest perfusion, a 'top-up' bolus of $0.07 \mathrm{mmol} / \mathrm{kg}$ was given to make a total contrast dose of $0.15 \mathrm{mmol} / \mathrm{kg}$. Late gadolinium enhancement imaging (LGE) was performed 10-15 min after the final injection of contrast.

CMR analyses and reporting were undertaken with cases randomly split between two experienced imaging cardiologists (GPM, ASHC). LV EF and volumes, wall thickness and perfusion were assessed using commercially available software (Argus, Siemens Healthineers, Erlangen, Germany). LV contours were drawn manually (excluding papillary muscles) to derive end-diastolic and end-systolic volumes and LVEF from the short-axis cine stack as reported by our group previously with excellent intraobserver and inter-observer variability [18]. Volumetric data were indexed to body surface area.

\section{Definitions of 'new diagnoses' from CMR}

MI was defined as high signal intensity area(s) on LGE involving at least the sub-endocardium in a coronary artery distribution and the segmental extent and transmurality were described. For ischaemia evaluation, in conjunction with LGE images, stress and rest perfusion images were semi-quantitatively assessed for reversible perfusion defects. The defects were categorized into ischaemia likely to be due to epicardial CAD or microvascular dysfunction [19]. Ischaemia was defined by the identification of inducible perfusion defects as per published Society for Cardiovascular Magnetic Resonance guidance [19]. Circumferential, sub-endocardial perfusion defects seen at least on one ventricular level or crossing coronary territories were reported as suggestive of microvascular dysfunction, albeit with the caveat that significant CAD could not be reliably excluded.

Constrictive pericarditis (e.g. diastolic septal bounce, pericardial effusion, thickening and hyperenhancement on LGE) and HCM were diagnosed based on established CMR parameters $[5,12,14,20]$. A diagnosis of $\mathrm{HCM}$ was considered in all patients with LV wall thickness of $\geq 15 \mathrm{~mm}$ [12]. In such cases, the degree and pattern of LVH and medical history (including hypertension, blood pressure control, anti-hypertensive medications) were considered to gauge whether wall thickness was proportionate or disproportionate. A characteristic spade-like configuration of the LV cavity and apical:basal wall thickness ratio $\geq 1.3$ was used to diagnose apical HCM [14]. The overall likelihood of HCM was categorized as definite or probable.

\section{Follow-up and endpoints}

Patients were followed up for a minimum of 6 months post-study entry. The primary endpoint was the combination of hospitalization for HF (defined as a hospital admission for which HF was the primary reason and which required diuretic, inotropic or intravenous nitrate therapy) or all-cause mortality. Hospital databases and patient records were sourced to obtain outcome data.

\section{Statistical analysis}

Statistical analyses were performed using SPSS (version 22, International Business Machines, Inc., Armonk, New York, USA). Probability (p) values $<0.05$ were considered statistically significant. Normality was assessed using the ShapiroWilk test, histograms and Q-Q plots. Normally distributed data are expressed as mean \pm SD. Non-parametric data are expressed as median (25-75\% interquartile range [IQR]). Categorical data are expressed as absolute numbers or percentages. Comparisons of means of 2 groups were performed using the independent samples $t$ test. The chisquare test was used to compare categorical data. Cohen's Kappa (K) was used to test for agreements of similarities in image grading between CMR and TTE ( $p>0.05$ was considered significant). Cox proportional hazard and multiple regression analyses were performed to determine which variables were related significantly to the composite endpoint of death and/or hospitalization with HF. BNP levels were $\log _{10}$ transformed and hazard ratios for subsequent analysis refer to 1 standard deviation (SD) increment of the transformed BNP. Only variables with a univariate $p$ value $<0.10$ were entered into subsequent multivariate analysis. Kaplan-Meier survival curves were used to demonstrate cumulative event-free rates in patients stratified into $2 \mathrm{CMR}$ groups ('no new diagnoses' versus 'new diagnoses') and a log rank test was used to test for statistical significance.

\section{Results}

A summary of the study overview, patients excluded and results are presented in Fig. 1. One hundred and ninety six patients attended for screening. Severe lung disease was the most common reason for exclusion. One hundred and eighty patients met the initial study inclusion criteria. The majority of patients who did not undergo subsequent CMR evaluation were either claustrophobic or had pacemakers.

A total of 154 patients underwent CMR, of whom 5 did not undergo stress perfusion imaging. Baseline characteristics of the CMR population stratified by the presence or absence of new CMR diagnoses, are summarized in Table 1. Patients with and without new diagnoses on CMR had similar baseline characteristics, including LV volumes and LVEF. The cohort had a wide age range (37-97 years) with the majority of patients over 65 years. Nearly onethird were in NYHA class III or IV. There was a high prevalence of obesity and hypertension and nearly half the patients had a history of atrial fibrillation and a similar proportion of diabetes. Approximately a fifth had chronic 


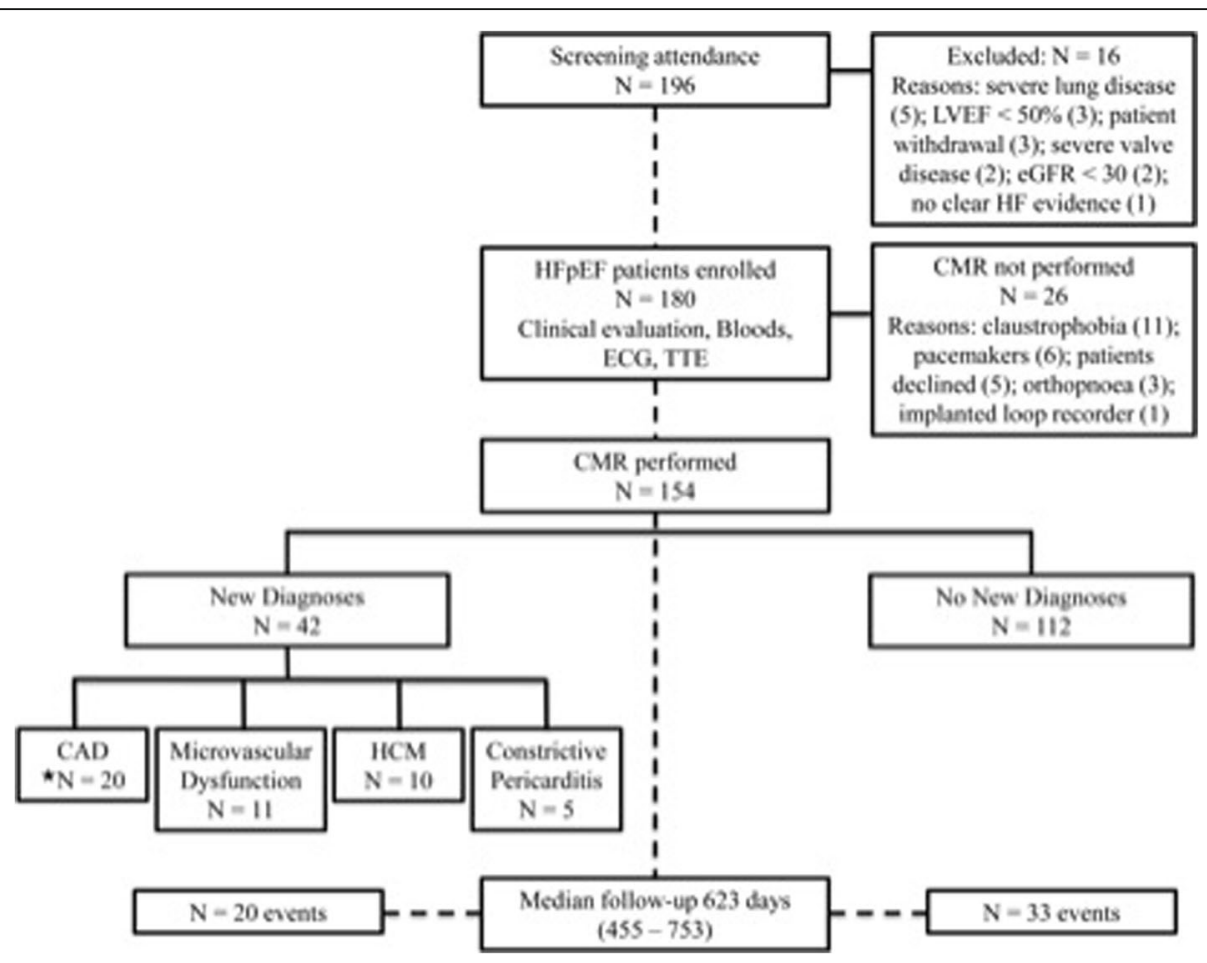

Fig. 1 Study overview. *Of the 20 patients with newly diagnosed coronary artery disease (CAD), 4 patients had concomitant hypertrophic cardiomyopathy (HCM)

lung disease. The proportion of patients with CAD at baseline was $21 \%$, including 15 patients with known MI.

\section{Imaging}

Overall, image quality was better for CMR compared to TTE (median grade: 3 vs 2 respectively). In those with a new diagnosis on CMR, this difference was also maintained and statistically significant (kappa statistic $[-0.021], p=0.72)$.

\section{'New diagnoses' from CMR}

CMR identified previously unknown diagnoses in 42 patients (27\%). The following new pathologies (see Fig. 1) were noted: epicardial CAD based on MI or ischaemia $(n$ $=20)$, microvascular dysfunction $(n=11), \operatorname{HCM}(n=10)$ and constrictive pericarditis $(n=5)$. Three patients with HCM had co-existent CAD (2 with new MI and 1 with ischaemia). One patient with constrictive pericarditis also had concurrent MI. Examples are shown in Fig. 2.

\section{CAD}

Fourteen patients had LGE indicating 'silent' MI (affecting 37 segments). Of these, 3 patients had known CAD at baseline but no prior known MI or pathological Q waves on ECG. On segmental analysis (see Fig. 3), infarcts were typically small, in a territory not subtended by the left anterior descending coronary artery (95\%) and of $<50 \%$ transmurality (68\%). Corresponding RWMAs on TTE were only reported in $38 \%$. As expected, the ability to diagnose MI by regional wall motion abnormality (RWMA) detectable by TTE worsened with diminishing transmurality of MI (0-50\% [24\%] versus $51-100 \%$ [67\%]). On review of the corresponding ECGs, only one case fulfilled the Q wave criterion for MI [15].

There were 31 patients with reversible perfusion defects and in 11 of these, the pattern suggested microvascular dysfunction. In the remaining 20 patients with ischaemia in an epicardial CAD pattern, 13 had no prior known CAD. Of these 13 patients, CMR detected a new diagnosis of MI in 4 patients. Accounting for these, $\mathrm{CAD}$ was newly diagnosed in 20 patients (new MI in 11 and new ischaemia in 9).

\section{HCM}

Findings consistent with HCM (definite: $n=4$; probable: $n=6$ ) were reported in CMR studies of $10 \mathrm{pa}$ tients. Individual patient characteristics are shown in Table 2. The main CMR phenotypic patterns of HCM were: asymmetrical septal hypertrophy (70\%), focal fibrosis on LGE (70\%) and maximal hypertrophy at the basal anteroseptum (50\%). With TTE, measured wall thickness was significantly lower (mean difference $2.3 \pm$ $2.2 \mathrm{~mm}, p<0.05)$, compared to CMR. TTE criteria for diagnosis of $\mathrm{HCM}$ were reported in only $50 \%$ of cases 
Table 1 Baseline characteristics of the patients who underwent CMR

\begin{tabular}{|c|c|c|c|c|}
\hline & All & $\begin{array}{l}\text { No new diagnoses } \\
\text { group }(n=112)\end{array}$ & $\begin{array}{l}\text { New diagnoses } \\
\text { group }(n=42)\end{array}$ & $p$ value \\
\hline \multicolumn{5}{|l|}{ Demographics } \\
\hline Age, years & $72 \pm 10$ & $73 \pm 9$ & $72 \pm 12$ & 0.61 \\
\hline Male & 78 (50.6) & $54(48.2)$ & $24(57.1)$ & 0.32 \\
\hline \multicolumn{5}{|l|}{ Clinical findings } \\
\hline Atrial fibrillation & $72(46.8)$ & $50(44.6)$ & $24(52.4)$ & 0.42 \\
\hline Heart rate (bpm) & $70 \pm 14$ & $70 \pm 14$ & $72 \pm 16$ & 0.57 \\
\hline Systolic blood pressure $(\mathrm{mmHg})$ & $143 \pm 25$ & $144 \pm 25$ & $146 \pm 26$ & 0.61 \\
\hline Diastolic blood pressure $(\mathrm{mmHg})$ & $74 \pm 12$ & $74 \pm 12$ & $74 \pm 13$ & 0.99 \\
\hline Body mass index $\left(\mathrm{kg} / \mathrm{m}^{2}\right)$ & $34 \pm 7$ & $34 \pm 7$ & $33 \pm 9$ & 0.66 \\
\hline \multicolumn{5}{|l|}{ NYHA } \\
\hline$|/| \mid$ & $106(68.8)$ & $77(68.8)$ & $29(69.0)$ & 0.97 \\
\hline III/IV & $48(31.2)$ & $35(31.3)$ & $13(31.0)$ & \\
\hline \multicolumn{5}{|l|}{ Medical History } \\
\hline Known coronary artery disease & $32(20.8)$ & - & - & - \\
\hline Hypertension & $139(90.3)$ & $111(89.3)$ & $39(92.9)$ & 0.60 \\
\hline Diabetes & 75 (48.7) & $54(48.2)$ & $21(50.0)$ & 0.88 \\
\hline $\begin{array}{l}\text { Chronic obstructive pulmonary } \\
\text { disease or asthma }\end{array}$ & $27(17.5)$ & $17(15.2)$ & $10(23.8)$ & 0.21 \\
\hline \multicolumn{5}{|l|}{ Chest radiography } \\
\hline Pulmonary edema & $110(71.4)$ & $79(70.5)$ & $31(73.8)$ & 0.69 \\
\hline \multicolumn{5}{|l|}{ Medication } \\
\hline Aspirin & $54(35.1)$ & $42(37.5)$ & $12(28.6)$ & 0.30 \\
\hline Beta-blocker & $99(64.3)$ & $74(66.1)$ & $25(59.5)$ & 0.45 \\
\hline ACEi or ARB & $130(84.4)$ & 97 (86.6) & $33(78.6)$ & 0.22 \\
\hline Statin & $97(63.0)$ & $70(62.5)$ & $27(64.3)$ & 0.84 \\
\hline Loop diuretic & $125(81.2)$ & $91(81.3)$ & $34(81.0)$ & 0.97 \\
\hline \multicolumn{5}{|l|}{ Biochemistry } \\
\hline Sodium (mmol/L) & $139 \pm 3.4$ & $139 \pm 3.6$ & $140 \pm 2.6$ & 0.39 \\
\hline Urea $(\mathrm{mmol} / \mathrm{L})$ & $8.7 \pm 3.8$ & $8.8 \pm 4.0$ & $8.3 \pm 3.5$ & 0.46 \\
\hline eGFR $\left(\mathrm{ml} / \mathrm{min}\right.$ per $\left.1.73 \mathrm{~m}^{2}\right)$ & $66 \pm 19$ & $66 \pm 19$ & $64 \pm 19$ & 0.46 \\
\hline BNP (ng/L, median, IQR) & $145(66-259)$ & $134 \pm(57.5-251)$ & $175 \pm(111-263)$ & ${ }^{*} 0.12$ \\
\hline \multicolumn{5}{|l|}{$C M R$} \\
\hline LVEF (\%) & $57 \pm 6$ & $57 \pm 6$ & $57 \pm 7$ & 0.98 \\
\hline LVEDVI $\left(\mathrm{ml} / \mathrm{m}^{2}\right)$ & $74 \pm 18$ & $73 \pm 17$ & $77 \pm 21$ & 0.26 \\
\hline LVESVI $\left(\mathrm{ml} / \mathrm{m}^{2}\right)$ & $33 \pm 11$ & $32 \pm 10$ & $34 \pm 13$ & 0.30 \\
\hline
\end{tabular}

Values are mean \pm SD or $\mathrm{n}(\%)$. The $p$ values are for the t-test or chi-square test. $A C E i$ angiotensin converting enzyme inhibitor; ARB $=$ angiotensin II receptor blocker, BNP B-type natriuretic peptide, CMR cardiovascular magnetic resonance imaging, eGFR estimated glomerular filtration rate, $L V E F$ left ventricular ejection fraction, LVEDVI left ventricular end-diastolic volume indexed to body surface area, LVESVI left ventricular end-systolic volume indexed to body surface area; $p$ value refers to $\operatorname{zlog}_{10}$ transformed BNP

of new CMR diagnosis of HCM. The pattern of LVH on TTE was primarily concentric.

\section{Constrictive pericarditis}

Constrictive pericarditis was identified in 5 patients, with at least 3 out of the 4 main diagnostic parameters for CMR present in all cases (see Table 3). Whilst pericardial thickening on CMR was universally reported in patients with constrictive pericarditis, this finding was not identified in any of the TTE reports. Furthermore, in 3 out of 4 patients, TTE failed to identify septal bounce that was observed with CMR. 

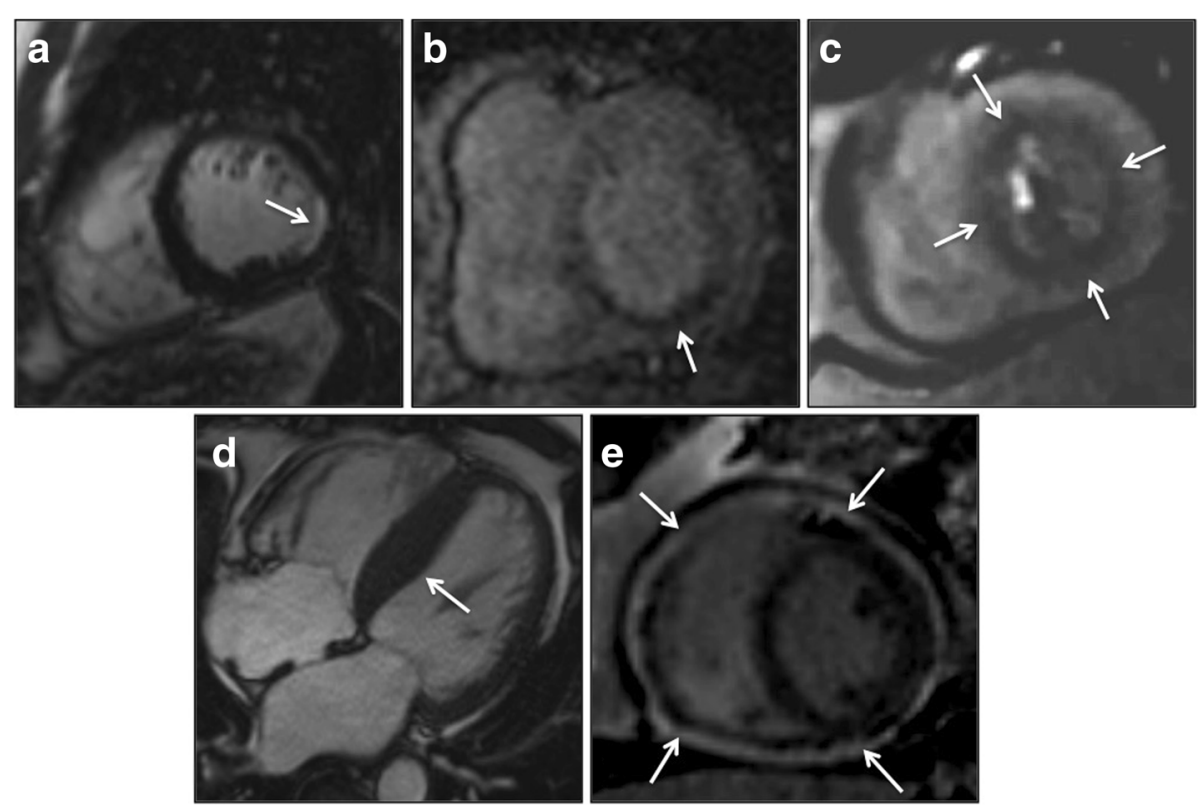

Fig. 2 Examples of typical findings in the 'new diagnoses' group. CMR images of: a sub-endocardial, inferolateral myocardial infarction of 25-50\% transmurality on LGE; $\mathbf{b}$ inferoseptal and inferior perfusion defect consistent with right coronary artery territory ischaemia; c global, concentric perfusion defect consistent with microvascular dysfunction; $\mathbf{d}$ horizontal long axis cine demonstrating asymmetrical septal hypertrophy in HCM; E) constrictive pericarditis with circumferential pericardial hyperenhancement on LGE; white arrows point towards pathology; LGE = late gadolinium enhancement imaging

\section{Clinical outcome}

During a median follow-up of 623 days (IQR 455753 ), there were a total of 53 events (19 deaths, 34 hospitalizations with HF). Of these, 'the new CMR diagnoses group' accounted for 20 events (8 deaths, 12 hospitalizations with HF). Event-free rates (Fig. 4) were significantly lower in the 'new CMR diagnoses' group $(52.4 \%$ vs $70.5 \%$, log rank test: $p<0.05)$. The results of univariate and multivariate Cox proportional hazards analysis to predict events are shown in Table 4. On multivariate analysis, a new CMR diagnosis (hazard ratio [HR]: 1.92; 95\% confidence interval

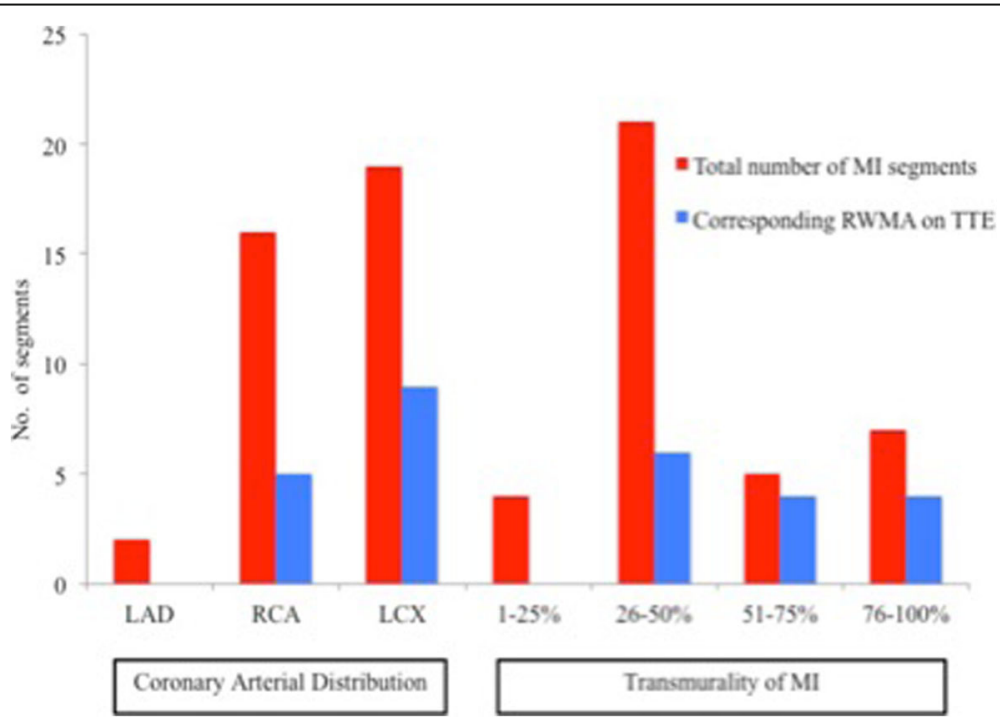

Fig. 3 Characteristics of newly diagnosed myocardial infarction according to coronary arterial distribution and transmurality. $L A D=$ left anterior descending artery; RCA = right coronary artery; LCX = left circumflex artery; \% transmurality of Ml is illustrated as 1-25, 26-50, 51-75, 76-100; RWMA = regional wall motion abnormality 
Table 2 Cox regression analysis for death and/or hospitalization with heart failure at minimum 6 month follow-up

\begin{tabular}{|c|c|c|c|c|}
\hline & $\begin{array}{l}\text { Univariate model, } \\
\text { HR }(95 \% \mathrm{Cl})\end{array}$ & $p$ & $\begin{array}{l}\text { Multivariate model, } \\
\text { HR }(95 \% \mathrm{Cl})\end{array}$ & $p$ \\
\hline \multicolumn{5}{|l|}{ Demographics } \\
\hline Age & $1.01(0.99-1.05)$ & 0.34 & & \\
\hline Gender & $1.48(0.84-2.60)$ & 0.17 & & \\
\hline \multicolumn{5}{|l|}{ Clinical Findings } \\
\hline Heart rate (b.p.m) & $1.00(0.98-1.02)$ & 0.64 & & \\
\hline $\begin{array}{l}\text { Systolic blood pressure } \\
(\mathrm{mmHg})\end{array}$ & $1.00(0.98-1.01)$ & 0.38 & & \\
\hline $\begin{array}{l}\text { Diastolic blood pressure } \\
(\mathrm{mmHg})\end{array}$ & $0.97(0.95-1.00)$ & 0.03 & $0.99(0.97-1.02)$ & 0.48 \\
\hline NYHA III/IV & $1.80(1.02-3.17)$ & 0.04 & $1.55(0.83-2.89)$ & 0.17 \\
\hline \multicolumn{5}{|l|}{ Medical history } \\
\hline Hypertension & $2.40(0.58-9.87)$ & 0.23 & & \\
\hline Diabetes & $1.03(0.59-1.79)$ & 0.91 & & \\
\hline \multicolumn{5}{|l|}{ Biochemistry } \\
\hline Sodium (mmol/L) & $0.97(0.90-1.05)$ & 0.45 & & \\
\hline Urea (mmol/L) & $1.09(1.02-1.15)$ & 0.01 & $1.10(1.01-1.21)$ & 0.04 \\
\hline eGFR $\left(\mathrm{ml} / \mathrm{min}\right.$ per $\left.1.73 \mathrm{~m}^{2}\right)$ & $0.99(0.97-1.00)$ & 0.07 & $1.01(0.99-1.03)$ & 0.37 \\
\hline ZLog BNP (ng/L) & $1.47(1.08-2.01)$ & 0.02 & $1.44(1.03-2.02)$ & 0.03 \\
\hline \multicolumn{5}{|l|}{ CMR findings } \\
\hline New diagnoses group & $1.75(1.00-3.07)$ & 0.05 & $1.92(1.06-3.45)$ & 0.03 \\
\hline
\end{tabular}

Abbreviations are as for Table 1 and $H R$ hazard ratio, $\mathrm{Cl}$ confidence interval

[CI]: 1.06 to $3.45 ; p<0.05), \log \mathrm{BNP}$ (HR: $1.44 ; \mathrm{CI}$ : 1.03 to $2.02 ; p<0.05$, and urea (HR: $1.10 ; \mathrm{CI}: 1.01$ to $1.21 ; p<0.05)$ were predictors of the primary endpoint.

\section{Discussion}

The principal finding in our study is that stress CMR unmasks potentially clinically relevant undiagnosed cardiac pathology in a significant proportion of patients (27\%) labelled as HFpEF after echocardiography. A clinically relevant proportion of our patients was identified as having hitherto unknown coronary artery disease or microvascular dysfunction. Moreover, despite being part of the TTE-based exclusion criteria at study entry, new cases of HCM and constrictive pericarditis were identified during subsequent CMR evaluation. Our observations suggest that previous intervention trials in HFpEF are likely to have included patients meeting one or more exclusion criteria, thereby possibly influencing treatment response. These additional pathologies, when grouped together in our cohort, were associated with adverse outcomes.

\section{'New CMR diagnoses'}

The reasons for the higher pick-up rate of new clinical diagnoses with CMR are multiple. Firstly, the overall image quality for TTE in our study was poor, reflecting the clinical profile of our challenging population, with a high prevalence of obesity, lung disease and atrial fibrillation [21]. These comorbidities are typical of HFpEF as reported in the literature [1]. Furthermore, the low feasibility (inadequate endocardial border definition in nearly one-third) and diagnostic utility of TTE in HF has previously been reported and is subject to wider limits of agreement compared with CMR [9, 22]. The ability of CMR to interrogate any imaging plane and perform in vivo tissue characterization (e.g. by LGE) makes this the reference standard for detection of new diagnoses in our cohort [9-11].

Previous reports quote a wide range for the prevalence of CAD in HFpEF, comprising primarily data from epidemiological studies and registries. Furthermore, the presence of CAD was variably based on patient reporting, use of insensitive and non-specific investigations (e.g. ECG, exercise treadmill tests), inconsistent diagnostic cut-offs for angiographic disease severity, and did not incorporate CMR [23]. In this study, CMR increased the overall proportion of significant CAD (silent MI and/or ischaemia) from $21 \%$ to $34 \%$, equivalent to a relative increase of $63 \%$. These findings (and microvascular dysfunction) might be expected, given the proportion of elderly, hypertensive and diabetic patients in our cohort [24]. Furthermore, these greater number of 'new' CAD diagnoses is perhaps unsurprising given that $\mathrm{CAD}$ was not part of our exclusion criteria. We used a practical 
Table 3 Characteristics of newly diagnosed hypertrophic cardiomyopathy patients

\begin{tabular}{|c|c|c|c|c|c|c|c|c|c|c|c|c|c|}
\hline \multirow[t]{2}{*}{ Patient } & \multirow[t]{2}{*}{ Age } & \multirow[t]{2}{*}{ HTN } & \multirow{2}{*}{$\begin{array}{l}\text { Image } \\
\text { modality }\end{array}$} & \multirow{2}{*}{$\begin{array}{l}\text { Image } \\
\text { grade }\end{array}$} & \multicolumn{2}{|c|}{ Maximal wall thickness } & \multicolumn{2}{|c|}{ Hypertrophy pattern } & \multirow[t]{2}{*}{ SAM } & \multirow[t]{2}{*}{ LVOTO } & \multicolumn{2}{|c|}{ LGE hyperenhancement } & \multirow{2}{*}{$\begin{array}{l}\text { Likelihood } \\
\text { of HCM }\end{array}$} \\
\hline & & & & & $\mathrm{mm}$ & region & ASH & Concentric & & & Mid-wall & Insertion point & \\
\hline \multirow[t]{2}{*}{ A } & 71 & + & TTE & 2 & 15 & Basal inferoseptum & - & + & - & - & $\mathrm{n} / \mathrm{a}$ & & Definite \\
\hline & & & CMR & 2 & 19 & Basal anteroseptum & + & - & - & - & + & + & \\
\hline \multirow[t]{2}{*}{${ }^{\mathrm{a} B}$} & 85 & - & TTE & 3 & 12 & Apical septum & - & + & - & - & $\mathrm{n} / \mathrm{a}$ & & Definite \\
\hline & & & CMR & 3 & 10 & Apical septum & - & - & - & - & - & - & \\
\hline \multirow[t]{2}{*}{ C } & 79 & + & TTE & 1 & 15 & Basal inferoseptum & - & + & + & - & $\mathrm{n} / \mathrm{a}$ & & Probable \\
\hline & & & CMR & 2 & 15 & Basal anteroseptum & + & - & - & - & - & + & \\
\hline \multirow[t]{2}{*}{ D } & 37 & - & TTE & 1 & 17 & Basal inferoseptum & u/a & u/a & u/a & $\mathrm{u} / \mathrm{a}$ & $\mathrm{n} / \mathrm{a}$ & & Definite \\
\hline & & & CMR & 3 & 22 & Basal inferoseptum & - & + & - & - & + & + & \\
\hline \multirow[t]{2}{*}{$E$} & 68 & + & TTE & 2 & 16 & Basal inferoseptum & - & + & - & - & $\mathrm{n} / \mathrm{a}$ & & Definite \\
\hline & & & CMR & 2 & 21 & Basal anteroseptum & + & - & - & - & + & - & \\
\hline \multirow[t]{2}{*}{$\mathrm{F}$} & 87 & + & TTE & 2 & 12 & Basal inferoseptum & - & + & + & + & $\mathrm{n} / \mathrm{a}$ & & Probable \\
\hline & & & CMR & 3 & 15 & Basal anteroseptum & + & - & + & + & + & + & \\
\hline \multirow[t]{2}{*}{ G } & 62 & + & TTE & 2 & 13 & Basal inferoseptum & - & + & + & - & $\mathrm{n} / \mathrm{a}$ & & Probable \\
\hline & & & CMR & 2 & 15 & Basal inferoseptum & + & - & + & - & - & - & \\
\hline \multirow[t]{2}{*}{$\mathrm{H}$} & 70 & + & TTE & 1 & 14 & Basal anteroseptum & - & + & - & - & $\mathrm{n} / \mathrm{a}$ & & Probable \\
\hline & & & CMR & 2 & 15 & Mid inferoseptum & + & - & - & - & + & - & \\
\hline \multirow[t]{2}{*}{ | } & 74 & - & TTE & 1 & 14 & Basal anteroseptum & - & + & - & - & $\mathrm{n} / \mathrm{a}$ & & Probable \\
\hline & & & CMR & 3 & 17 & Basal inferoseptum & - & + & - & - & - & - & \\
\hline \multirow[t]{2}{*}{ J } & 72 & + & TTE & 1 & 16 & Basal anteroseptum & - & + & - & - & $\mathrm{n} / \mathrm{a}$ & & Probable \\
\hline & & & CMR & 3 & 18 & Basal anteroseptum & + & - & - & - & + & - & \\
\hline
\end{tabular}

Abbreviations: $\mathrm{TTE}=$ transthoracic echocardiography; $\mathrm{CMR}=$ cardiac magnetic resonance; $\mathrm{HTN}=$ hypertension, $\mathrm{LGE}=$ late gadolinium enhancement imaging; $\mathrm{u} / \mathrm{a}=$ unable to assess; $\mathrm{n} / \mathrm{a}=$ not applicable; $-=$ absent; $+=$ present

Image grade: 1 = poor; 2 = fair; 3 = good

Diagnostic considerations for hypertrophic cardiomyopathy (HCM): LV wall thickness $\geq 15 \mathrm{~mm}$, asymmetrical septal hypertrophy (ASH - septal: free wall thickness ratio $>1.3$ ), apical HCM if apical wall thickness $>15 \mathrm{~mm}$ or apical:basal wall thickness ratio $\geq 1.3$, left ventricular outflow tract obstruction (LVOTO) and systolic anterior motion of the mitral valve (SAM)

${ }^{a}$ Note: Patient B was diagnosed with apical HCM (spade-like configuration of the LV cavity and apical: basal wall thickness ratio $\geq 1.3$ )

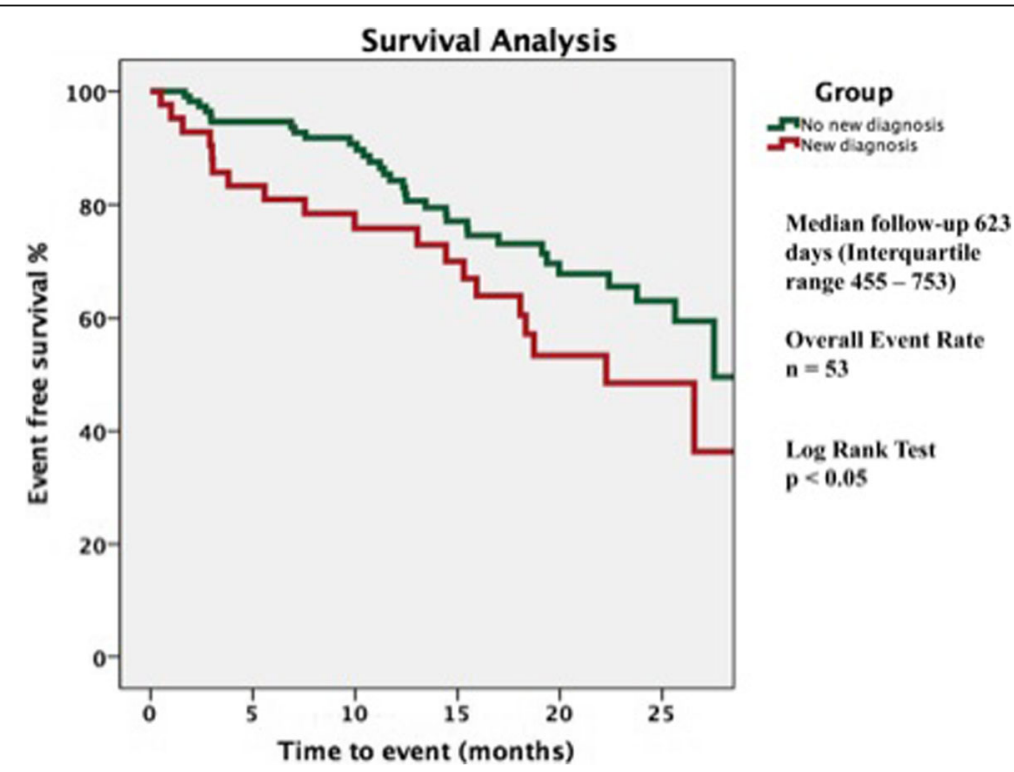

Fig. 4 Kaplan Meier analysis for the composite endpoint of death and/or hospitalization with heart failure. Nil 
Table 4 Imaging characteristics of newly diagnosed constrictive pericarditis patients

\begin{tabular}{|c|c|c|c|c|c|c|c|c|c|c|}
\hline \multirow[t]{2}{*}{ Patient } & \multicolumn{2}{|c|}{ Image grade } & \multicolumn{2}{|c|}{ Pericardial thickening } & \multicolumn{2}{|c|}{ Pericardial effusion } & \multicolumn{2}{|c|}{ Septal bounce } & \multirow{2}{*}{$\begin{array}{c}\text { Septal } E^{\prime} \geq 9 \mathrm{~cm} / \mathrm{s} \\
\text { TTE }\end{array}$} & \multirow{2}{*}{$\begin{array}{c}\text { Pericardial } \\
\text { enhancement } \\
\text { CMR }\end{array}$} \\
\hline & TTE & CMR & TTE & CMR & TTE & CMR & TTE & CMR & & \\
\hline $\bar{A}$ & 2 & 2 & - & + & + & + & - & - & - & + \\
\hline B & 2 & 3 & - & + & - & + & - & + & + & + \\
\hline C & 1 & 3 & - & + & - & - & - & + & + & + \\
\hline D & 1 & 2 & - & + & - & + & - & + & + & - \\
\hline$E$ & 1 & 3 & - & + & + & + & + & + & - & + \\
\hline
\end{tabular}

Abbreviations: TTE transthoracic echocardiography, CMR cardiac magnetic resonance; $-=$ absent; $+=$ present

Image grade: 1 = poor; 2 = fair; 3 = good

definition of HFpEF and current clinical guidelines [25] for $\mathrm{HF}$ do not mandate routine investigation for CAD unless accompanied by anginal symptoms recalcitrant to medical therapy. Additionally, the higher numbers of 'silent' CAD could also be explained by the inability of some patients to provoke clinical symptoms due to limited exercise capacity owing to co-morbidities. Conversely, exertional breathlessness may represent angina equivalent. The typical patterns of infarction (small number of segments and $\leq 50 \%$ transmurality) in our study are in keeping with overall preservation of LVEF. In such cases, the diagnostic accuracies of both ECG (Q wave) and TTE (RWMAs) are low in concordance with published literature [26].

Diagnosing HCM represents an imaging challenge in this cohort of patients. The latest HCM diagnostic guidelines [12] advocate a morphological description of imaging in suspected subjects. These guidelines are also more inclusive of considering HCM as a diagnosis in any patients whereby increased LV wall thickness cannot solely be explained by abnormal loading conditions. CMR features supportive of HCM in hypertensive patients include a more asymmetric pattern of LVH and LGE at the insertion points and in segments of maximal LV wall thickening $[27,28]$. Furthermore, LGE is reportedly present in $65 \%$ with HCM, similar to our cohort [12].

HCM is characterized by non-specific diverse patterns of hypertrophy with or without left ventricular outflow tract obstruction or systolic anterior motion of the mitral valve $[12,14,29]$. In HFpEF, LVH is a common finding [1] and co-existing conditions such as ageing, obesity and hypertension are additional confounders [30]. Furthermore, hypertensive heart disease classically presents with concentric hypertrophy and wall thickness rarely exceeds 15-16 mm [28]. Deciphering the pattern of $\mathrm{LVH}$ according to mass and relative wall thickness calculations traditionally used in TTE is fraught with intrinsic methodological limitations [31]. These factors along with sub-optimal image quality [29] and the very high prevalence of hypertension $(90 \%)$ may explain the underreporting of HCM by
TTE in our cohort. In our study, patients who met wall thickness criteria for HCM on TTE were not reported as likely HCM most probably due to a predominant concentric pattern of LVH. Whilst TTE traditionally risks overestimating wall thickness (e.g. oblique cuts) [12], underestimation has been noted in a small (12\%) proportion, especially if confined to the inferolateral, anterolateral or apical segments. In contrast, the superior endocardial definition afforded by CMR allows a more precise measurement of LV wall thickness and hypertrophy [29].

Current TTE diagnostic criteria for constrictive pericarditis have lower sensitivities compared to CMR (pericardial thickening: $36 \%$ vs $88 \%$, septal bounce: $62 \%$ vs $81 \%)[5,20]$. In our cohort, the majority of these TTE parameters were not detected, which again is a likely reflection of poor image quality.

\section{Implications}

Our CMR findings reinforce the marked clinical heterogeneity in HFpEF [1] and provide alternative explanations for symptoms in a significant minority of patients. Survival following silent MI is comparable to known MI [32]. Importantly, diagnosis by CMR enables initiation of effective secondary prevention treatment and guides revascularization, given that most affected myocardial segments identified in our cohort were viable [13]. Our data suggest that screening for significant $C A D$ should be undertaken in patients with suspected HFpEF. A diagnosis of HCM has implications for both patients and relatives. CMR improves risk stratification and may enable earlier initiation of therapies such as implantable defibrillator devices [12]. Constrictive pericarditis is potentially curable and pericardial enhancement on LGE may predict treatment response [5].

\section{Implications for current HFpEF clinical trials}

Our study has important implications and ramifications for HFpEF clinical trials and current treatment 
strategies. Variable definitions of HFpEF and phenotypic heterogeneity displayed in prior studies have previously been proposed as a key reasons for treatment failure [1, 3]. This has led to a paradigm shift in focus to study 'purer' subsets of HFpEF resulting in more detailed mechanistic studies. Our CMR study findings provide additional explanations for such poor outcomes whereby TTE remains the primary entry tool for trial enrolment. Our data suggests that TTE alone is incapable of rigorously excluding imaging phenocopies of HFpEF prior to study entry. Such conditions have alternate pathophysiological mechanisms, respond differently to existing therapies and contribute to adverse outcomes. While TTE is comparatively more extensively available, and therefore attractive for clinical trial design, access to CMR is rapidly increasing. Furthermore, CMR refines the diagnosis and sub-categorises HFpEF into 'purer forms' and alternative pathologies, enabling disease-specific tailored therapies, and provides prognostic data.

The routine use of stress CMR in HFpEF patients should refine diagnosis and treatment strategies as we move towards an era of precision medicine. However, further randomised trials are needed to assess the wider impact of CMR in terms of clinical outcome, resource utilization and cost-effectiveness.

\section{Limitations}

The definition of HFpEF used in our study was not in accordance with current European Society of Cardiology (ESC) guidelines [8]. However, we took a pragmatic approach to reflect a real world setting. In particular, the presence of diastolic dysfunction was not a pre-requisite for study entry since recent contemporary clinical trials have highlighted normal diastolic function at rest in approximately a third of such patients [7]. Although all patients meeting inclusion criteria were invited, 26 out of 180 (14\%) did not undergo CMR, which might raise concerns about its applicability to the wider HFpEF population. Whilst chronic obstructive pulmonary disease is quite prevalent in the clinical scenario of HFpEF, we only excluded patients with severe disease (and likewise severe valvular disease) to minimise the contribution from alternate causes of HF symptoms. Besides our cohort still comprised chronic obstructive pulmonary disease subjects in nearly one-fifth who underwent CMR. Six patients with pacemakers did not undergo CMR: at the time the study was conducted, our centre was not implanting CMR conditional devices. Although all CMR scans were performed solely at $3 \mathrm{~T}$, we expect the study findings to be similar with a $1.5 \mathrm{~T}$ system.

Discriminating microvascular dysfunction from global coronary ischaemia can be challenging with CMR and raises the possibility of under-reporting of CAD.
Furthermore, patients did not have stress echocardiography which may have identified more patients with ischaemia. In this cohort of patients with multiple risk factors for $\mathrm{LVH}$, ultimately the imaging diagnosis of $\mathrm{HCM}$ is one of exclusion. However, the most recent ESC guidelines recommend defining $\mathrm{HCM}$ in patients with $\mathrm{LVH} \geq 15 \mathrm{~mm}$ not solely explained by loading conditions [12]. Our CMR reports were generated using a clinical protocol exclusive of $\mathrm{T} 1$ and $\mathrm{T} 2$ mapping which were not routinely used at the time of study conduct. T1 mapping may have unmasked further hypertrophic phenotypes [12] such as cardiac amyloid and AndersonFabry's disease, and T2 mapping may have been helpful in cases of constrictive pericarditis [5].

While the CMR reports were generated by GPM and ASHC, clinical endpoints were collated by PK who was not blind to CMR results. However, the HF hospitalization events were clearly objectively defined (see methods section) and assessment of vital status is robust. Some patients may have had hospitalizations exclusive of our hospital. However, there should be no systematic bias for those with or without 'new' diagnoses.

\section{Conclusions}

In HFpEF, CMR identifies previously undetected pathology in a significant proportion of patients. This group of additional diagnoses is associated with worse outcomes and is an independent predictor of death and hospitalization due to HF.

\section{Abbreviations}

ACEi: Angiotensin converting enzyme inhibitor; ARB: Angiotensin II receptor blocker; BNP: B-type natriuretic peptide; CAD: Coronary artery disease;

$\mathrm{Cl}$ : Confidence interval; CMR: Cardiovascular magnetic resonance imaging; ECG: Electrocardiogram; EF: Ejection fraction; eGFR: Estimated glomerular filtration rate; $F E V_{1}$ : Forced expiratory volume; FVC: Forced vital capacity; HCM: Hypertrophic cardiomyopathy; HF: Heart failure; HFpEF: Heart failure with preserved ejection fraction; HFrEF: Heart failure with reduced ejection fraction; HR: Hazard ratio; LGE: Late gadolinium enhancement imaging; LV: Left ventricle/left ventricular; LVEDVI: Left ventricular end-diastolic volume indexed to body surface area; LVEF: Left ventricular ejection fraction; LVESVI: Left ventricular end-systolic volume indexed to body surface area; LVH: Left ventricular hypertrophy; MI: Myocardial infarction; NYHA: New York Heart Association classification; RWMA: Regional wall motion abnormalities; TTE: Transthoracic echocardiography

\section{Acknowledgements}

The authors would like to thank the CMR radiographers at Glenfield Hospital for image acquisition. GP McCann is supported by a NIHR Career Development Fellowship (2014-07-045).

\section{Funding}

This work was supported by and falls under the portfolio of research conducted within the National Institute for Health Research (NIHR) Leicester Cardiovascular Biomedical Research Unit. Overall project Grant: IRS IS_BRU_0211_20033.

\section{Availability of data and materials}

The datasets generated during and/or analysed during the current study are available from the corresponding author (GPM) upon reasonable request. 


\section{Authors' contributions}

PK recruited the patients, supervised the CMR scans and study visits (with AS), analysed the data, performed the statistical analysis and drafted the manuscript. ASHC and GPM reported the CMR scans. AMM and JM performed and reported the TTE scans. All authors critically revised the manuscript for important intellectual content and approved the final manuscript.

\section{Ethics approval and consent to participate}

All study participants provided written informed consent. The study was approved by the National Research Ethics Service Committee East Midlands - Nottingham 1 on July 24, 2012 (Reference: 12/EM/0222). ClinicalTrials.gov Identifier: NCT03050593.

\section{Consent for publication}

Not applicable.

\section{Competing interests}

The authors declare that they have no competing interests .

\section{Publisher's Note}

Springer Nature remains neutral with regard to jurisdictional claims in published maps and institutional affiliations.

\section{Author details}

${ }^{1}$ Department of Cardiovascular Sciences and National Institute for Health Research (NIHR), University of Leicester, Leicester Cardiovascular Biomedical Research Unit, Glenfield Hospital, Groby Road, Leicester LE3 9QP, UK. ${ }^{2}$ Kettering General Hospital, Kettering, UK. ${ }^{3}$ National Institute for Health Research (NIHR) Leicester Cardiovascular Biomedical Research Unit, Glenfield Hospital, Leicester, UK. ${ }^{4}$ Department of Cardiovascular Sciences and National Institute for Health Research (NIHR), University of Leicester, Leicester Cardiovascular Biomedical Research Unit, Cardiovascular Medicine, Glenfield Hospital, Leicester, UK. ${ }^{5}$ Department of Cardiovascular Sciences and National Institute for Health Research (NIHR), Medicine and Therapeutics, University of Leicester, Leicester Cardiovascular Biomedical Research Unit, Glenfield Hospital, Leicester, UK. ${ }^{6}$ Department of Cardiovascular Sciences and National Institute for Health Research (NIHR), Cardiac Imaging, University of Leicester, Leicester Cardiovascular Biomedical Research Unit, Glenfield Hospital, Leicester, UK.

Received: 24 August 2017 Accepted: 14 December 2017

Published online: 11 January 2018

\section{References}

1. Komajda M, Lam CS. Heart failure with preserved ejection fraction: a clinical dilemma. Eur Heart J. 2014;35(16):1022-32.

2. Owan TE, Hodge DO, Herges RM, Jacobsen SJ, Roger VL, Redfield MM Trends in prevalence and outcome of heart failure with preserved ejection fraction. N Engl J Med. 2006;355(3):251-9.

3. Paulus WJ, van Ballegoij JJ. Treatment of heart failure with normal ejection fraction: an inconvenient truth! J Am Coll Cardiol. 2010:55(6):526-37.

4. Borlaug BA, Paulus WJ. Heart failure with preserved ejection fraction: pathophysiology, diagnosis, and treatment. Eur Heart J. 2011;32(6):670-9.

5. Cosyns B, Plein S, Nihoyanopoulos P, Smiseth O, Achenbach S, Andrade MJ, Pepi M, Ristic A, Imazio M, Paelinck B, et al. European Association of Cardiovascular Imaging (EACVI) position paper: multimodality imaging in pericardial disease. Eur. Heart J. Cardiovasc.Imaging. 2015:16(1):12-31.

6. Sanderson JE. Heart failure with a normal ejection fraction. Heart. 2007;93(2):155-8.

7. Pitt B, Pfeffer MA, Assmann SF, Boineau R, Anand IS, Claggett B, Clausell N, Desai AS, Diaz R, Fleg $J$, et al. Spironolactone for heart failure with preserved ejection fraction. N Engl J Med. 2014;370(15):1383-92.

8. Paulus WJ, Tschope C, Sanderson JE, Rusconi C, Flachskampf FA, Rademakers FE, Marino P, Smiseth OA, De Keulenaer G, Leite-Moreira AF, et al. How to diagnose diastolic heart failure: a consensus statement on the diagnosis of heart failure with normal left ventricular ejection fraction by the heart failure and echocardiography associations of the European Society of Cardiology. Eur Heart J. 2007;28(20):2539-50.

9. Bellenger NG, Burgess MI, Ray SG, Lahiri A, Coats AJ, Cleland JG, Pennell DJ. Comparison of left ventricular ejection fraction and volumes in heart failure by echocardiography, radionuclide ventriculography and cardiovascular magnetic resonance; are they interchangeable? Eur Heart J. 2000:21(16):1387-96.

10. Jenkins C, Moir S, Chan J, Rakhit D, Haluska B, Marwick TH. Left ventricular volume measurement with echocardiography: a comparison of left ventricular opacification, three-dimensional echocardiography, or both with magnetic resonance imaging. Eur Heart J. 2009;30(1):98-106.

11. Leong DP, De Pasquale CG, Selvanayagam JB. Heart failure with normal ejection fraction: the complementary roles of echocardiography and CMR imaging. JACC Cardiovasc. Imaging. 2010;3(4):409-20.

12. Authors/Task Force $m$, Elliott PM, Anastasakis A, Borger MA, Borggrefe $M_{\text {, }}$ Cecchi F, Charron P, Hagege AA, Lafont A, Limongelli G, et al. 2014 ESC guidelines on diagnosis and Management of Hypertrophic Cardiomyopathy: the task force for the diagnosis and management of hypertrophic Cardiomyopathy of the European Society of Cardiology (ESC). Eur Heart J. 2014:35(39):2733-79.

13. Kim RJ, Wu E, Rafael A, Chen EL, Parker MA, Simonetti O, Klocke FJ, Bonow RO, Judd RM. The use of contrast-enhanced magnetic resonance imaging to identify reversible myocardial dysfunction. N Engl J Med. 2000;343(20):1445-53.

14. Suzuki J, Shimamoto R, Nishikawa J, Yamazaki T, Tsuji T, Nakamura F, Shin WS, Nakajima T, Toyo-Oka T, Ohotomo K. Morphological onset and early diagnosis in apical hypertrophic cardiomyopathy: a long term analysis with nuclear magnetic resonance imaging. J Am Coll Cardiol. 1999;33(1):146-51.

15. Horan LG, Flowers NC, Johnson JC. Significance of the diagnostic Q wave of myocardial infarction. Circulation. 1971;43(3):428-36.

16. Picard MH, Adams D, Bierig SM, Dent JM, Douglas PS, Gillam LD, Keller AM, Malenka DJ, Masoudi FA, McCulloch M, et al. American Society of Echocardiography recommendations for quality echocardiography laboratory operations. J Am Soc Echocardiogr. 2011;24(1):1-10.

17. Singh A, Ford I, Greenwood JP, Khan JN, Uddin A, Berry C, Neubauer S, Prendergast B, Jerosch-Herold M, Williams B, et al. Rationale and design of the PRognostic importance of Mlcrovascular dysfunction in asymptomatic patients with aortic Stenosis (PRIMID-AS): a multicentre observational study with blinded investigations. BMJ Open. 2013;3(12):e004348.

18. Steadman CD, Jerosch-Herold M, Grundy B, Rafelt S, Ng LL, Squire IB, Samani NJ, McCann GP. Determinants and functional significance of myocardial perfusion reserve in severe aortic stenosis. JACC Cardiovasc. Imaging. 2012;5(2):182-9.

19. Schulz-Menger J, Bluemke DA, Bremerich J, Flamm SD, Fogel MA, Friedrich MG, Kim $\mathrm{R}$, von Knobelsdorff-Brenkenhoff F, Kramer CM, Pennell DJ, et al. Standardized image interpretation and post processing in cardiovascular magnetic resonance: Society for Cardiovascular Magnetic Resonance (SCMR) board of trustees task force on standardized post processing. J Cardiovasc Magn Reson. 2013;15:35.

20. Yared K, Baggish AL, Picard MH, Hoffmann U, Hung J. Multimodality imaging of pericardial diseases. JACC Cardiovasc. Imaging. 2010;3(6):650-60.

21. Mulvagh SL, Rakowski H, Vannan MA, Abdelmoneim SS, Becher H, Bierig SM, Burns PN, Castello R, Coon PD, Hagen ME, et al. American Society of Echocardiography consensus statement on the clinical applications of ultrasonic contrast agents in echocardiography. J Am Soc Echocardiogr. 2008:21(11):1179-201. quiz 1281

22. Hare JL, Brown JK, Marwick TH. Performance of conventional echocardiographic parameters and myocardial measurements in the sequential evaluation of left ventricular function. Am J Cardiol. 2008;101(5):706-11.

23. Shah SJ. Evolving approaches to the management of heart failure with preserved ejection fraction in patients with coronary artery disease. Curr. Treat. Options Cardiovasc. Med. 2010;12(1):58-75.

24. Arenja N, Mueller C, Ehl NF, Brinkert M, Roost K, Reichlin T, Sou SM, Hochgruber T, Osswald S, Zellweger MJ. Prevalence, extent, and independent predictors of silent myocardial infarction. Am J Med. 2013;126(6):515-22.

25. Ponikowski P, Voors AA, Anker SD, Bueno H, Cleland JG, Coats AJ, Falk V, Gonzalez-Juanatey JR, Harjola VP, Jankowska EA, et al. 2016 ESC guidelines for the diagnosis and treatment of acute and chronic heart failure: the task force for the diagnosis and treatment of acute and chronic heart failure of the European Society of Cardiology (ESC)developed with the special contribution of the heart failure association (HFA) of the ESC. Eur Heart J. 2016;37(27):2129-200.

26. Jaarsma C, Schalla S, Cheriex EC, Smulders MW, van Dongen I, Nelemans PJ, Gorgels AP, Wildberger JE, Crijns HJ, Bekkers SC. Incremental value of cardiovascular magnetic resonance over echocardiography in the detection of acute and chronic myocardial infarction. J Cardiovasc Magn Reson. 2013:15:5.

27. Puntmann VO, Jahnke C, Gebker R, Schnackenburg B, Fox KF, Fleck E, Paetsch I. Usefulness of magnetic resonance imaging to distinguish hypertensive and hypertrophic cardiomyopathy. Am J Cardiol. 2010;106(7):1016-22. 
28. To AC, Dhillon A, Desai MY. Cardiac magnetic resonance in hypertrophic cardiomyopathy. JACC Cardiovasc. Imaging. 2011;4(10):1123-37.

29. Maron MS, Maron BJ, Harrigan C, Buros J, Gibson CM, Olivotto I, Biller L, Lesser JR, Udelson JE, Manning WJ, et al. Hypertrophic cardiomyopathy phenotype revisited after 50 years with cardiovascular magnetic resonance. J Am Coll Cardiol. 2009:54(3):220-8.

30. Karam R, Lever HM, Healy BP. Hypertensive hypertrophic cardiomyopathy or hypertrophic cardiomyopathy with hypertension? A study of 78 patients. J Am Coll Cardiol. 1989;13(3):580-4.

31. Lang RM, Bierig M, Devereux RB, Flachskampf FA, Foster E, Pellikka PA, Picard MH, Roman MJ, Seward J, Shanewise J, et al. Recommendations for chamber quantification. Eur J Echocardiogr. 2006;7(2):79-108.

32. Kwong RY, Chan AK, Brown KA, Chan CW, Reynolds HG, Tsang S, Davis RB. Impact of unrecognized myocardial scar detected by cardiac magnetic resonance imaging on event-free survival in patients presenting with signs or symptoms of coronary artery disease. Circulation. 2006;113(23):2733-43.

Submit your next manuscript to BioMed Central and we will help you at every step:

- We accept pre-submission inquiries

- Our selector tool helps you to find the most relevant journal

- We provide round the clock customer support

- Convenient online submission

- Thorough peer review

- Inclusion in PubMed and all major indexing services

- Maximum visibility for your research

Submit your manuscript at www.biomedcentral.com/submit
Biomed Central 